\title{
Townscape and Urban Planning: My Research Agenda at Cal Poly
}

\author{
Lorenza Pavesi \\ PhD Candidate, University of São Paulo, Brazil; \\ Visiting Researcher, CRP Department, Cal Poly.
}

\begin{abstract}
Continuing its tradition of supporting visiting researchers, this last academic year the CRP Department received Lorenza Pavesi, a doctoral study at the University of São Paulo, Brazil. She spent a busy year studying the impact that the British Townscape approach to urbanism had on American education and practice, by visiting places and diving deep into books and library archives. In this article she writes about her experience.
\end{abstract}

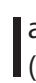
arrived at the City and Regional Planning (CRP) Department in July 2013, as a Visiting Scholar with a twelve-month scholarship from FAPESP, a research sponsoring foundation from the State of Sao Paulo, Brazil. Now it is August 2014 and I am back in Brazil. These lines serve as an account of my activities during this period, but also as a thankful note to all (faculty, staff, students, and friends) who contributed to making my stay in Cal Poly so special. I hope my account will inspire students to spend time abroad and be open to new experiences.

\section{My Trajectory and Why Cal Poly}

This is my story. I am a PhD candidate at FAUUSP, the University of São Paulo's School of Architecture and Urbanism. If rankings are to be trusted, USP ranks among the world's top seventy universities and the best in Latin America. In my opinion FAU-USP is a great place to study and I am extremely lucky to have professor Paulo Bruna as my advisor. A well respected academic and successful professional, he runs one of the most important architecture firms in Brazil and is definitely one of the best lecturers I have ever had. ${ }^{1}$

Since I don't really have a very traditional or linear professional trajectory I'll write a few words about my background. I was born in a tiny medieval town near Venice, Italy and when I was a teenager I moved to Brazil with my family. I have travelled the world both with my family and alone, working as a translator and in other capacities. In the early nineties I enrolled at the Free University of Berlin, Germany and witnessed the fall of the infamous wall. My interests in history, town planning, architecture, and design definitely intensified then. Subsequently,

\footnotetext{
${ }^{1}$ See Paulo Bruna's work at <http://www.paulo-bruna.com.br>
}

I spent some time back in Brazil and then in Ireland. I ended up enrolling at Coventry University, England, where I received a first class degree in Visual Communication.

I am neither an architect nor a planner but quickly realized that Coventry-a British industrial city that was devastated by German bombs in 1940-is an interesting case to study. Coventry is not famous for being a pretty city but it is definitely the place to be if you, like me, have a strong interest in second post-war reconstruction in Europe, and in architectural and historical preservation in general. In Coventry I met a very kind antiquarian, historian, and book dealer who introduced me to some of the most important titles on City Planning and post-war reconstruction. One title attracted me most. At first it was the book as an artifact itself: big, bold, printed in different types of paper due to the post-war rationing, great black and white photos with splashes of red arrows and text, and fantastic drawings. Then, I was literally overwhelmed by the text. The book was Outrage, authored by the British critic lan Nairn, beautifully illustrated by Gordon Cullen, and published as a special edition by the influential London based Architectural Review magazine.

And since I was about to graduate at the time I chose to write my final work on visual perception and psychology. My main references were the Gestalt theories: the work of J.J. Gibson and the theory of "affordances", as well as Gordon Cullen's "serial vision" from his Townscape method. That's when my love affair with urban design started, although at the time I had no idea where it was going to take me. Long story short: I went back to Brazil and received a Masters degree at FAU-USP with a thesis on the British critic lan Nairn and the birth of Townscape as an urban design methodology, which Nairn strongly de- 
fended. ${ }^{2}$ Fascinated by Nairn's remarkable writing skills and eccentric personality, I discovered how far Townscape principles had resonated outside Great Britain.

I decided that this topic deserved a deeper analysis and started my PhD studies, also at FAU-USP, pursuing a thesis on the flow of urban planning principles across England, the United States, Italy, and Brazil with special reference to the diffusion of Townscape as an urban design methodology: how did it spread, through which instruments, who were the main authors and planners involved in this diffusion, and what were the results? This led me to apply for a scholarship to spend a year in the United States, at Cal Poly's CRP Department, and study under the supervision of professor Vicente del Rio, whose work I had studied and admired for years. I share Vicente's passion for travelling, literature, history, and urban design, and he couldn't have been more generous with his time and knowledge. All the CRP faculty was always very supportive and welcoming, as was everybody I met at the College of Architecture and Environmental Design (CAED).

\section{About my research}

One of the main objectives of my research period in the United States was to gain access to publications, archives and correspondence (and of course to pick Vicente's brain on Urban Design) in order to examine the exchange of ideas between British and American planners and the interest of theorists and planners in the Townscape methodology. I cannot publish definitive results yet but during this amazing year at Cal Poly I came across more than I was looking for. I discovered authors that are, in my opinion, definitely underestimated by historiography such as Grady Clay, David Crane, and Peter Blake, and found out more about well-known authors such as Victor Gruen, Jane Jacobs, and William H. Whyte. The last two had a clear interest in the Townscape theories and were in contact with Townscape authors such as Gordon Cullen and lan Nairn.

The evidence of a strong connection between Townscape advocates and American planners is not always clear, sometimes the proximity is very subtle and not directly acknowledged, and it's not easy to find a project in the United States that was built entirely according to Townscape principles. However, some of its core principles did clearly strike a chord in the United States during the second postwar period, such as the anti-suburb discourse and the call for compact and walkable cities. As we all know, the term "Urban Design" was first used in 1956 when Harvard University held the first conference on urban design, organized by José Luis Sert with the participation of prominent architects, historians, and critics including Louis Mumford, Jane Jacobs, and Victor Gruen. At this conference Sert announced Urban Design as a new academic field concerned with the physical form of the city, and added that the urban designer should above all

\footnotetext{
${ }^{2}$ See Lorenza Pavesi's article on lan Nairn in FOCUS 10, 2013.
}

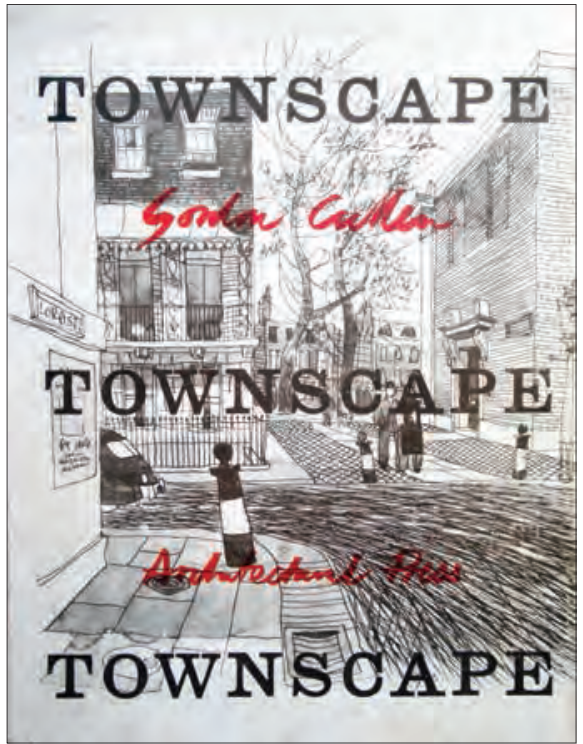

Cover of the first edition (1961) of Gordon

Cullen's influencial book.

believe in cities and their importance and value to human progress and culture. This provided a platform for the launch of Harvard's Urban Design Program in 1959-60, a model later adopted by other Anglo-Saxon universities.

Another genealogy can be found in the mid 1950s with the efforts by the Rockefeller Foundation to respond to the United States housing crisis through research initiatives such as a program called "Studies in Urban Design." Between 1955 and 1965 they sponsored research projects on urban design by scholars such as Kevin Lynch, Gyorgy Kepes, Jane Jacobs, Edmund Bacon, Christopher Alexander, Christopher Tunnard, lan McHarg, Edward Gutkind, and Townscape advocate lan Nairn.

The Foundation's first grant in urban design studies in April 1954 was for a basic research project formulated by Gyorgy Kepes and Kevin Lynch at MIT to study the fundamentals of human perception and understanding of the urban environment. Its goal was to feed the center's main research and take a more scientific approach to urban aesthetics. In fact, this project was born of a seminar on "visual form of the city", organized by Lynch in 1951 (Lawrence, 2006). According to Orillard (2009), although the seminar's bibliography was almost entirely composed of articles from the British magazine Architectural Review, cradle of the Townscape philosophy, there was a clear attempt to transform the magazine's writing into a more academic discourse, for example, by converting the word "vision" to "perception" and by referring to environmental psychology and anthropology. This research led to the establishment of a new field of investigation, which clearly fed the recently formed field of Urban Design in which Lynch and his collaborators worked until the 1980 s.

Another research project funded by the Rockefeller Foundation between 1957 and 1961 was developed at Yale University by 
Canadian landscape architect Christopher Tunnard. It focused on aesthetic issues at the boundaries between urban and rural areas, and proposed to develop new standards for suburban sprawl and urbanization in rural areas.

For my research I also went to UCLA's Charles E. Young Research Library where I found Victor Gruen's papers and other useful publications in the special collections archive. I also took a fantastic walking tour of downtown Los Angeles with the L.A. Conservancy, which I strongly recommend to students.

\section{A Little Beyond Research}

Beyond the research itself, another reason why the University of São Paulo and FAPESP encourage their PhD students to spend study periods at international institutions is the opportunity to interact with other researchers and get to know the culture of other institutions. Being used to historiographical and theoretical approaches, it was particularly useful to experience Cal Poly's "learning by doing" approach. I took professors Vicente del Rio's, William Siembieda's, and Kelly Main's wonderful courses, and used every opportunity to chat and exchange information with faculty. I was also very impressed by the students' enthusiasm and participation both in class and in the many activities offered on campus. It was refreshing and very endearing that, despite the age difference, young undergraduate and graduate students were always keen to know about my experience and asked about my research. I attended countless talks and lectures and tried hard to make the most out of my time. I travelled, volunteered, explored every corner of the city, and talked to everyone who was willing to lend me an ear.

I had the opportunity to travel California; a very valuable and revealing experience (and very enjoyable too of course). For most of my trips I used public transport and although California's love affair with the car and the freeways is well known, I was surprised at the ease with which I was able to move from one place to the other by transit. Encouraged by Professor

Unfortunately neglected, the Fullton Mall in Fresno was an important project by Victor Gruen (architect) and Garrett Eckbo (landscape architect), possibly influenced by the Townscape theory. (photo by Brian Harley; www.creativecommons.com)

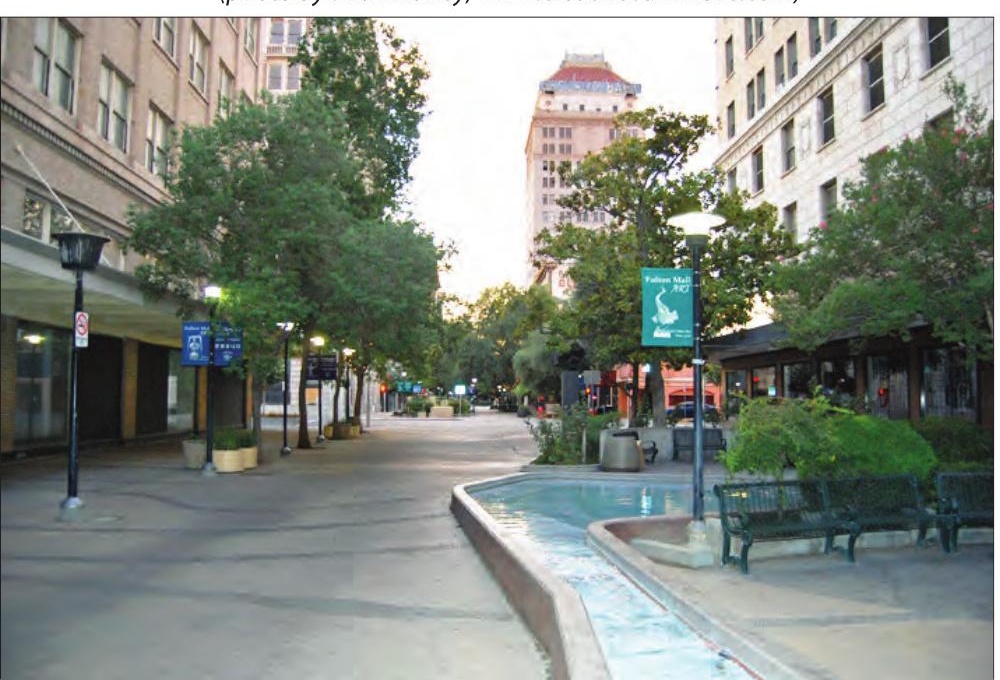

Siembieda, I visited Santa Barbara and read about its urban design guidelines while sipping a coffee and looking at the beautiful coast from the Pacific Surfliner's window. I toured Los Angeles by bus with only a paper map and no smartphone or gps device. I obviously got lost but found my way again thanks to the kindness of strangers (Californians are the most generous and kind people I have ever met).

The long distances were often overwhelming and the pre-exposure generated by cinema and literature obviously played a role in turning places, even the dreariest ones, into a thrilling experience for me. But from a European or Latin American perspective Los Angeles is crazy, vibrant, creative, energetic, chaotic, and absolutely exciting. Even being stuck in the traffic was exciting. I travelled south, always by bus, to lovely San Clemente but left out San Diego for my next visit. Big Sur, camping, hiking, surfing, wine tasting, and dancing in the Mission plaza. It was exhilarating. I visited Carmel and Monterey (I am a big fan of Steinbeck and was curious how the city recreated the landscape described in the Cannery Row). And of course I visited San Francisco: trolley, bus, underground, and car. I was, at the same time, outraged and fascinated by gentrified areas such as the Dogpatch, Hayes Valley, and Mission, and by the invasion of tourists (and seals) in Fisherman's Wharf. As I have a special interest in the architect and town planner Victor Gruen, I visited some of his projects in Los Angeles and also the Fullton Mall in Fresno.

Despite the hard work and the huge amount of bureaucracy involved (it took me almost 4 months to obtain the scholarship and all the necessary documents for the visa) I can say that it was definitely worth it. I encourage every student to spend time abroad. Go with your mind (and your heart) open to new experiences and embrace local culture and way of life: talk to people, learn a new language, learn new skills and get involved, observe, and increase your repertoire. This will be part of who you are and nobody will ever take this back from you. If there is anything I can do to help planning students to travel abroad, or anything else, please feel free to contact me at <lore.pavesi@gmail.com>. And if you come across information that could help me with my thesis, I'll be eternally grateful. Thank you CRP for the warm welcome and for making my time in SLO so special.

\section{References}

Lawrence, P. L. (2006). The death and life of urban design: Jane Jacobs, The Rockefeller Foundation and the new research in urbanism, 1955-1965. Journal of Urban Design, 11(2), 145-171. doi:10.1080/13574800600644001

Orillard, C. (2009). Tracing urban design's 'Townscape' origins: Some relationships between a British editorial policy and an American academic field in the 1950s. Urban History, 36, 284-302. doi:10.1017/S0963926809006294 